\title{
Icelandic Groundfish Survey Data Used to Improve Precision in Stock Assessments
}

\author{
O. K. Pálsson, E. Jonsson, S. A. Schopka, G. Stefansson and B. AE. Steinarsson \\ Marine Research Institute \\ Skulagata 4, P. O. Box 1390, 121 - Reykjavik, Iceland
}

\begin{abstract}
The main objective of this study was to improve the precision of stock assessments of demersal fish in Icelandic waters, with particular emphasis on cod. Sampling was carried out on approximately 600 stations in the Iceland shelf area in March 1985 and again in March 1986. Stations were distributed in the survey area through a semi-randomly stratified process. A standardized bottom trawl was designed for the sampling and the data collected included length measurements, otolith samples and sex determination, as well as information on the environment and fishing gear.

Results are presented for cod, haddock, saithe, redfish, catfish and long rough dab. The distributions of the different species indicate common nursery grounds in the northern part of the survey area. The youngest age-groups were generally not fully represented in the survey. Pronounced diurnal catch variations were observed for catfish and redfish.

Age disaggregated stock indices of the gadoid species are well correlated with virtual population analysis (VPA) values. However, the total stock indices differ in their proportion of the VPA stock size. In comparison with previous surveys, the precision of stock indices has been increased markedly through this survey for all species except saithe. This is basically the result of an increased number of stations. Skipper-selected stations (non-random) generally gave higher aggregated indices than random ones, although statistically significant differences are exceptional. On a length disaggregated basis, however, a highly significant difference was observed for all species.
\end{abstract}

\section{Introduction}

Groundfish species have been investigated in Icelandic waters since the turn of the century, when the pioneer of fishery biology in Iceland, Bjarni Saemundsson, began his research. In 1930, Arni Fridriksson began his fisheries research in Icelandic waters, and since then groundfish investigations have been conducted annually. In the mid-1950's a regular, standardized sampling of the demersal fish stocks in Icelandic waters commenced and during each summer from then on, a survey of approximately 20 standard stations was carried out covering mainly the inshore areas of the continental shelf. These surveys continued into the late 1960 's.

An extensive survey of the biology and abundance of juvenile cod was initiated in 1976 (Pálsson, MS 1984). This survey was carried out in different seasons and covered the continental shelf north and east of Iceland. During each survey, a grid of approximately 80 fixed stations was worked. This survey has yielded basic results for the prediction of year-class strength of cod. However, comparable results for other relevant demersal species have not been available from the survey.
Mature cod migrate in some years from Greenland waters to Icelandic fishing grounds. The migrations vary from year to year and were especially pronounced in 1980 and 1981. Such migrations make traditional stock estimates based on virtual population analysis (VPA) techniques, invalid. Since quantitative information on the extent of the migrations is not available, a fishery independent stock estimate is required.

In 1982, a more extensive stratified-random survey was initiated in order to investigate the biology and abundance of cod and other demersal species (Schopka et al., MS 1983). This survey, which was carried out in late winter and autumn, included approximately 200 stations, and covered all important demersal fish stocks in Icelandic waters. However, the achieved precision (17-28\% in numbers) of the late winter stock size estimates for cod was considered unsatisfactory for management purposes.

Substantial improvements in the planning methods and effort of groundfish surveys in Icelandic waters have now been achieved, particularly during the last decade. However, the need for improvements in the precision of stock size estimates, as a basis of modern 
fisheries management, has become even more urgent. Under these circumstances the present groundfish project was initiated. The main objective was to obtain a more precise abundance estimate of the demersal fish stocks, particularly cod, by a fisheries independent method. The first survey was carried out during 8-25 March 1985, when 595 stations were sampled, and the second survey was carried out 5-25 March 1986 covering 586 stations. The material sampled is too extensive to present in detail in this paper, however, results are presented for cod (Gadus morhua morhua (L.)), haddock (Melanogrammus aeglefinus (L.)), saithe (Pollachius virens (L.)), redfish (Sebastes marinus (L.)), catfish (Anarhichas lupus lupus L.) and long rough dab (Hippoglossoides platessoides limandoides (Bloch)). Except for the long rough dab, these are the major exploited demersal fish stocks in Icelandic waters.

\section{Methods}

\section{General}

According to statistical theory, the standard error is approximately inversely proportional to the square root of the number of observations. The gain in precision by increasing the number of stations was considered using the following formula (Grosslein, 1971) and data from groundfish surveys in March and April 1982-84:

$$
\mathrm{n}=\frac{1}{\mathrm{~V}} \sum_{\mathrm{h}} \frac{\mathrm{W}_{\mathrm{h}}^{2} \mathrm{~S}_{\mathrm{h}}^{2}}{\mathrm{w}_{\mathrm{h}}}
$$

where $\mathrm{n} \quad$ number of stations

$$
\begin{aligned}
& W_{h}^{2}=\begin{array}{l}
\text { area of the } h^{\text {th }} \text { stratum divided with total } \\
\text { area of all strata }
\end{array} \\
& S_{h}^{2}=\text { variance of catches in the } h^{\text {th }} \text { stratum } \\
& W_{h}=\frac{n_{h}}{n} \text { the observed relative sampling effort } \\
& \text { in } h^{\text {th }} \text { stratum }
\end{aligned}
$$

and $V=$ desired variance of the stratified mean.

In the calculations the average of the variances in catches of cod in each stratum were used. An increase in the number of stations from 200 to 500 would reduce the relative standard error, $V_{r}$, from 21 to $13 \%$, with

$$
V_{r}=\frac{S}{\bar{x} \sqrt{n-1}} 100
$$

where $\bar{x}=$ stratified mean,

and $S=$ sample variance of stratified mean.

Further increase would yield relatively limited additional gain in precision. However, during a survey, the planned number of sets is bound to be reduced because of rough bottom, net damage or other reasons. Furthermore, distribution and density patterns may vary over time, necessitating larger sample size. Therefore, 600 stations were considered a reasonable effort to reach the objectives of the project.

From the experience of earlier surveys, the month of March was selected as the most suitable time for the survey as diurnal vertical migrations are then less pronounced than in the autumn. Also, the spawning stock gathers on the southwestern grounds during this time and is therefore more easily available for surveying than in other seasons. Furthermore, for interpretation of the results it was considered essential to sample in the same season as previously. These arguments prevailed despite the fact that the geographic distribution of the cod seems to be more patchy in late winter than in autumn. It was expected that stationary gears (gillnets and longlines) might hinder the sampling during the spawning season, however, this was the case only on relatively few trawl stations.

The area of investigation covers the Icelandic shelf to the $500 \mathrm{~m}$ depth contour. Below $600 \mathrm{~m}$ very few commercial species of demersal fish are recorded except redfish (Sebastes marinus (L.)) and Greenland halibut (Reinhardtius hippoglossoides (Walbaum)). As cod are sometimes caught abundantly below $400 \mathrm{~m}$ in the commercial fishery, the $500 \mathrm{~m}$ isobath was chosen as a depth limit for the present survey.

Employment of commercial fishing vessels is necessary in order to work the 600 stations within the time limit of 2-3 weeks. The relatively short time limit is essential since the month of March marks the beginning of the spawning season of the cod. Therefore, sampling must be carried out quickly in order to minimize possible bias because of spawning migrations and also because the scientific advice resulting from the survey should be available during April in order to be included in management considerations. As standardization is important, five stern-trawlers, identical in size (462 BWT, length overall $47.1 \mathrm{~m}$ ), engine power and overall design, were leased.

Fishermen, mainly the captains of the research trawlers, were involved in planning the project on aspects such as gear standardization and stratification of the survey area with respect to fish abundance. The cooperation with fishermen is based on the main objective of the project; to increase precision and reliability of stock size estimates of relevant fish stocks, especially cod, through the integration of fishermen's experience, and knowledge of fish behavior and migrations, as well as the topography of the fishing grounds. However, it requires a careful study to evaluate the specific benefits of the fishermen's contribution. 


\section{Survey design}

In earlier groundfish surveys in Icelandic waters, stratification was based on depth zones as well as geographic and hydrographic boundaries (Schopka et al., MS 1983). This stratification was considered to indicate different fish density. The present stratification scheme was based on pre-estimated cod density patterns derived from commercial as well as research vessel catch data, which were summarized by "statistical squares". Thus in this design, cod density is based on actual data instead of general geographic or hydrographic guidelines in earlier surveys. In addition, the statistical square basis allows more flexibility in post-stratifications with respect to different species.

Based on biological and hydrographic considerations, the survey area was divided into a northern and a southern area (Fig. 1). A total of 600 stations were divided between the two areas, roughly in proportion to their size, and considering that $25-30 \%$ of the total cod stock at the time of the survey would be located in the southern area. Thus, 425 stations were positioned in the northern area and 175 in the southern one. Each area was divided into statistical squares of one half degree latitude and one degree longitude, on which the stratification scheme was based.

The allocation of statistical squares to strata was based on the estimated density of cod in each square. Information on cod density was derived from three different sources: the trawler captains and their advisors graded each square with respect to their experience of fishing in March. Commercial fisheries data yielded additional information on cod density, as did results from previous research surveys. A scale of 1 to 6 reflects the estimated variability in cod density in the northern area, and 1 to 4 in the southern one (Table 1 ).

Ten strata were constructed from the statistical squares, 6 in the northern area and 4 in the southern one (Fig. 1). Statistical squares in each strata are not necessarily adjacent, which allows more possibilities in constructing homogeneous strata with regard to fish density. This stratification scheme also allows flexibility to construct different strata for different analyses without modifying the basic system. Stations were allocated among strata in direct proportion to the product of the area of each stratum and its estimated cod den-

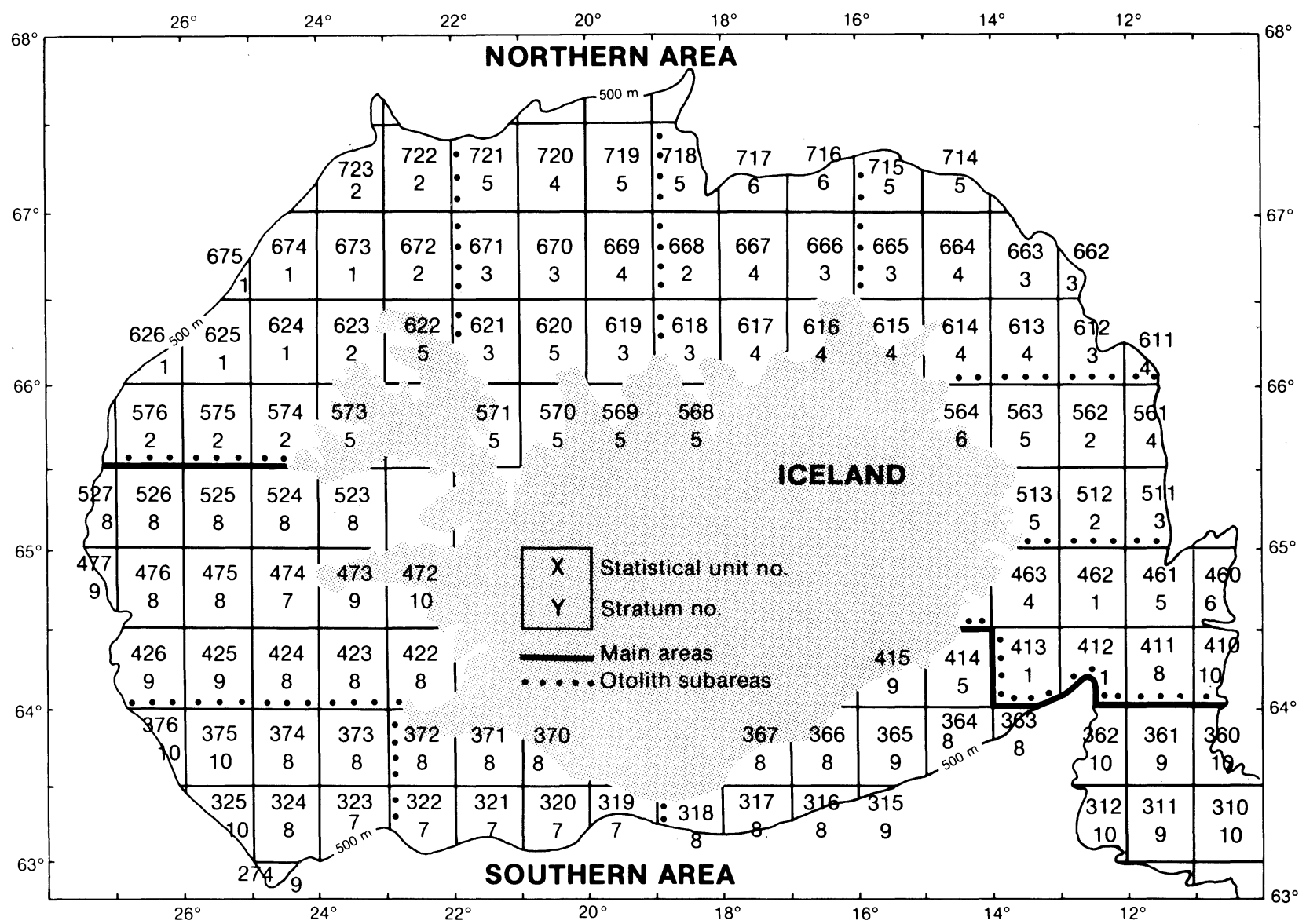

Fig. 1. The survey area within the 500-m depth contour showing the division boundaries for northern and southern areas, the allocation of statistical square numbers to strata, and the boundaries of otolith subareas. 
TABLE 1. The allocation of stations to strata in proportion to the area of the strata and the estimated density of cod.

\begin{tabular}{|c|c|c|c|}
\hline $\begin{array}{c}\text { Stratum } \\
\text { No. }\end{array}$ & Density & $\begin{array}{c}\text { Area } \\
\left(\mathrm{nm}^{2}\right)\end{array}$ & $\begin{array}{l}\text { No. of } \\
\text { stations }\end{array}$ \\
\hline \multicolumn{4}{|c|}{ Northern area } \\
\hline 1 & 6 & 5,125 & 103 \\
\hline 2 & 5 & 6,724 & 112 \\
\hline 3 & 4 & 6,441 & 86 \\
\hline 4 & 3 & 7,549 & 76 \\
\hline 5 & 2 & 6,282 & 42 \\
\hline 6 & 1 & 1,916 & 6 \\
\hline \multicolumn{4}{|c|}{ Southern area } \\
\hline 7 & 4 & 3,550 & 34 \\
\hline 8 & 3 & 14,432 & 105 \\
\hline 9 & 2 & 5,280 & 26 \\
\hline 10 & 1 & 4,189 & 10 \\
\hline
\end{tabular}

sity, as shown in Table 1. Finally, the trawl stations of a stratum were allocated to each square within the stratum in direct proportion to the area of the square.

Stations within each statistical square were divided equally between fishermen, and project members from the Marine Research Institute (MRI). MRI project members selected random positions for their stations. For the random selection each statistical square was divided into 120 sequentially numbered rectangles of $1.5 \mathrm{~min}$ longitude and $2.5 \mathrm{~min}$ latitude in size. The position of the lower left corner of a selected rectangle was used as midpoint of the tow, from which fishermen decided on the direction. A given rectangle was trawled only once. Commercial fishermen on the other hand, were asked to fix their stations in each square in accordance with their knowledge and experience of fishing and fishing grounds. Trawling was done both day and night, and sampling was distributed uniformly over the $24 \mathrm{hr}$.

This sampling method may be classified as "semirandom stratified" since only half of the stations are randomly selected. However, in future surveys the same stations will be repeated, leading to a stratified systematic survey design.

Clearly, the current arrangement of stratification and analysis does not adhere strictly to the usual theory of random-stratified sampling and analysis. The analysis is exclusively based on strata. However, the randomization or allocation of stations based on statistical squares within each stratum, leads to a more uniform distribution of stations than would random sampling within a stratum as a whole.

The squares within a stratum can be considered homogeneous with respect to long-term average population density. In a given year, however, the density will not be homogeneous within a stratum due to migrational movements. This will lead to higher concentra- tions in some squares, which leads to the necessity for sampling from each square. In stratified sampling schemes one needs to consider the tradeoffs between homogeneity within each stratum versus the sample size used in each. Small strata will lead to smaller sample sizes and possible failures of assumptions of normality.

\section{Fishing gear}

Standardization of the bottom trawl is essential in groundfish surveys. The trawl shown in Fig. 2 was standardized in cooperation between the scientists of $\mathrm{MRI}$ and the trawler skippers. The main consideration for standardization was that the trawl should effectively sample groundfish species, especially cod, of different lengths ensuring adequate data for the catchable stock as well as the recruiting year-classes. The trawl should also be maneuverable on different types of bottom substrates, and still retain a high level of catchability and physical performance at all depths of trawling.

This trawl type is, apart from the smaller mesh size in the aft belly and the codend, very similar to commercial bottom trawls presently used in Iceland. The mesh size of the trawl is relatively small $(135 \mathrm{~mm})$ in the front part of the net, where commercial trawlers frequently use 200 or $180 \mathrm{~mm}$. In the belly the mesh size is reduced to $80 \mathrm{~mm}$, and the extension piece and the codend are covered on the inside with $40-\mathrm{mm}$ netting.

The main feature of the net frame is a heavy groundrope, weighing approximately $4,200 \mathrm{~kg}$ in air and about $1,900 \mathrm{~kg}$ in sea water. The purpose of this heavy groundrope is to prevent as far as possible the escape of cod and some other species under the fishing line. The average height of the middle of the headline, as measured during the survey in 1985 , was $3.07 \mathrm{~m}$. Some small and exhausted fish are likely to escape through the wings and the square but escapement will not be significant in the aft belly and codend (Pálsson and Thorsteinsson, MS 1985).

The horizontal distance between the wing-ends (or the otter boards) could not be measured. Based on measurements on similar trawl designs and on data from the flume tank in Hirtshals, Denmark, the average distance between the wing ends is estimated to be $17 \mathrm{~m}$. This figure is, however, believed to depend very much on the depth, i.e. the distance decreases with increasing depth. In order to keep the catchability of the trawl as constant as possible at all fishing depths, the length of the bridles was extended from 35 to 45 fath when fishing in water deeper than 100 fath. Considering the sampling performance of this trawl design, it would be expected that slow and/or small fish might, to some extent, get overrun by the bridles since big and effective otter boards $(1,750 \mathrm{~kg})$ are used with rather long bridles. 


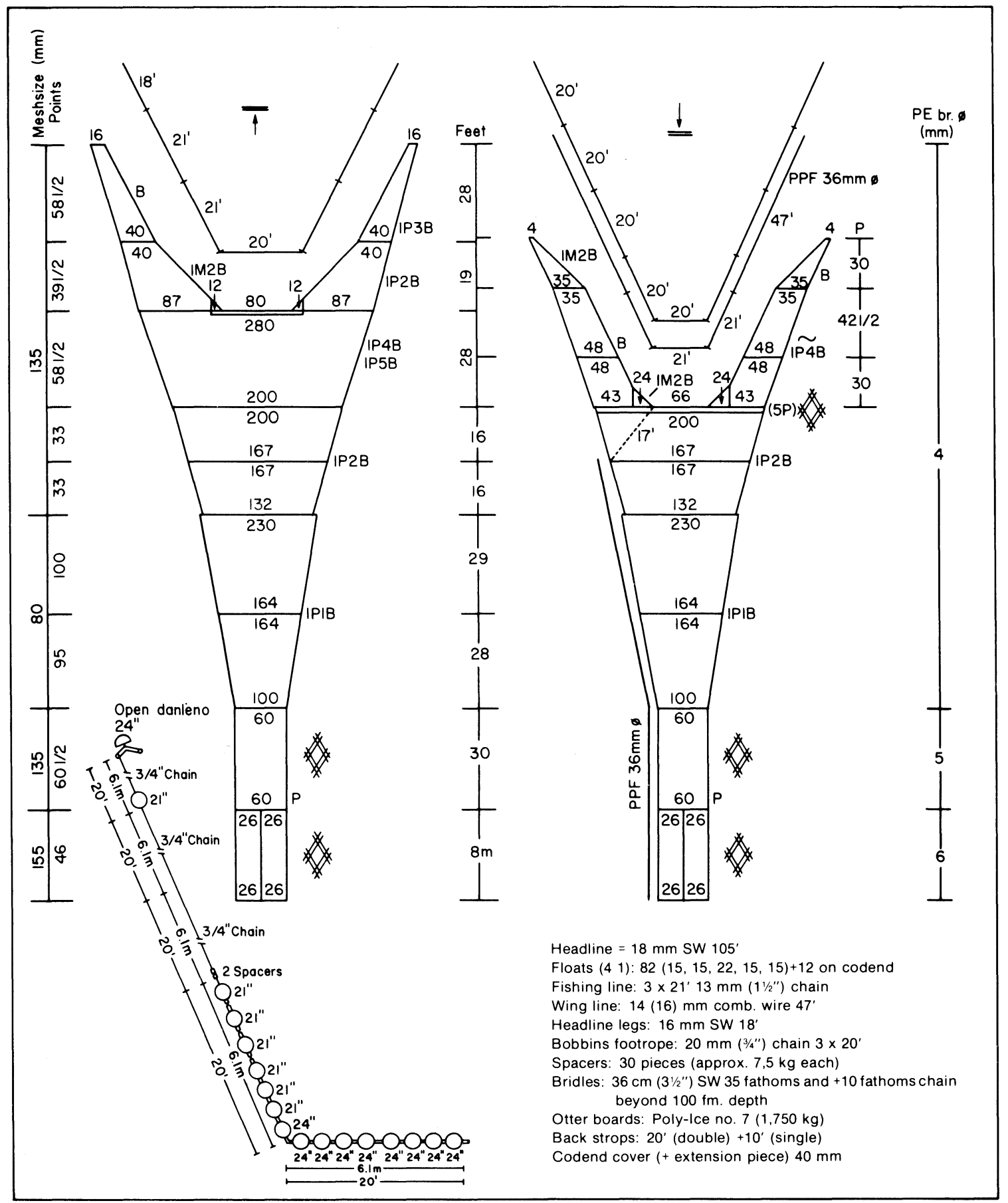

Fig. 2. Standardized bottom trawl used during the Icelandic Groundfish Survey.

The fishing method was standardized as far as possible and the standard towing speed was 3.8 knots over the bottom and the towing distance was 4.0 naut. miles. In case of hangup or other malfunction, a haul was considered valid if the towing distance was at least 2 naut. miles. In case of marked damage of the trawl netting, especially codend and belly, the tow was repeated in an adjacent position.

Scope, i.e. the ratio of warp length used to depth, could not be fixed as different fishing conditions may call for a different scope at a given depth. As a rule a standard scope of 3:1 was recommended. With regards to weather, it was decided to stop trawling when the 
wind force exceeded 8 on the Beaufort scale with corresponding sea state.

\section{Data collection}

The data collection may be divided into three categories: trawl station data, trawl catch data, and environmental observations. The trawl station data recorded were position, time, direction and depth of the tow, distance towed and trawling speed. In addition, information on trawl performance was recorded.

The trawl catch data included length measurements, and age determination from otolith samples (Table 2) and sex determination. The sampling of otoliths was performed in a length stratified procedure for each fish species in each of 10 subareas (Table 3, Fig. 1). No weighing of fish was done at sea and the biomass calculations presented in this paper are based on constant length-weight relationships from earlier data.

In the environmental category the following meteorological and hydrographic data were recorded for each trawl station: wind force (Beaufort scale) and direction, air temperature, weather conditions, cloud coverage, sea state, ice conditions and barometric pressure. Sea-surface and near-bottom temperature were recorded by means of a Scanmar Sonde. If possible, speed and direction of the surface current during a

TABLE 2. Number of fish mesured and aged by species in groundfish surveys carried out during 8-25 March 1985 and 5-25 March 1986

\begin{tabular}{lrrrrr}
\hline & \multicolumn{2}{c}{ Measured } & & \multicolumn{2}{c}{ Aged } \\
\cline { 2 - 3 } \cline { 6 - 6 } Species & \multicolumn{1}{c}{1985} & 1986 & & 1985 & 1986 \\
\hline Cod & 104,467 & 100,802 & & 2,690 & 3,025 \\
Haddock & 44,612 & 103,148 & & 1,966 & 1,955 \\
Saithe & 3,216 & 2,948 & & 1,253 & 841 \\
Redfish & 67,136 & 74,218 & & \\
Catfish & 18,946 & 20,620 & & 1,867 & 1,788 \\
Long rough dab & 38,112 & 46,385 & & \\
\hline
\end{tabular}

TABLE 3. Plan for stratified sampling of otoliths in each subarea (Fig. 1) giving the number of fish by species sampled in $5 \mathrm{~cm}$ length groups.

\begin{tabular}{ccccc}
\hline \hline $\begin{array}{c}\text { Length } \\
\text { interval } \\
(\mathrm{cm})\end{array}$ & $\begin{array}{c}\text { Cod } \\
\text { Saithe } \\
\text { Ling } \\
\text { Blue ling }\end{array}$ & $\begin{array}{c}\text { Haddock } \\
\text { Catfish } \\
\text { Greenland } \\
\text { halibut }\end{array}$ & $\begin{array}{c}\text { Tusk } \\
\text { Argentine } \\
\text { Plaice }\end{array}$ & Halibut \\
\hline $0-24$ & 10 & 10 & 10 & 10 \\
$25-39$ & 10 & 10 & 15 & 10 \\
$40-49$ & 10 & 15 & 20 & 10 \\
$50-54$ & 15 & 15 & 20 & 10 \\
$55-59$ & 15 & 15 & 30 & 10 \\
$60-69$ & 15 & 20 & 30 & 10 \\
$70-79$ & 20 & 25 & 30 & 10 \\
$80-89$ & 20 & 30 & 30 & 10 \\
$\geqslant=90$ & 30 & 30 & 30 & 10 \\
\hline
\end{tabular}

tow was estimated. Only a small part of the environmental data were included in the present analyses.

\section{Statistical calculations}

The equations used to compute the stratified mean and its standard error (Cochran, 1953) were:

$$
\begin{gathered}
\bar{Y}_{s t}=\frac{1}{A} \sum_{i=1}^{k} \bar{Y}_{i} A_{i} \\
V\left(\bar{Y}_{s t}\right)=\frac{1}{A^{2}} \sum_{i=1}^{k} \frac{A_{i}^{2} S_{i}^{2}}{n_{i}} \\
S_{\bar{Y}_{S t}}=\sqrt{V\left(\bar{Y}_{s t}\right)}
\end{gathered}
$$

where $\bar{Y}_{\text {st }}=$ stratified mean catch per haul

$\mathrm{V}\left(\overline{\mathrm{Y}}_{\overline{\mathrm{st}}}\right)=$ sample variance of the $\mathrm{i}$-th stratum

$\mathrm{S}_{\bar{Y}_{\text {st }}}=$ standard error of the stratified mean

A = survey area

$\mathrm{A}_{\mathrm{i}} \quad=$ area of the $\mathrm{i}$-th stratum

$Y_{i} \quad=$ mean catch-per-tow in the $i$-th stratum

$\mathrm{s}_{\mathrm{i}}^{2} \quad=$ variance of catches in the $\mathrm{i}$-th stratum

$\mathrm{n}_{\mathrm{i}} \quad=$ number of tows in the $\mathrm{i}$-th stratum

and $\mathrm{k}=$ number of strata.

The equation applied for the biomass indices is:

$$
B=\bar{Y}_{\text {st }} \frac{A}{\bar{a}}
$$

where $B=$ biomass index

and $\overline{\mathrm{a}}=$ area swept per tow,

and the standard error $S$ of the biomass indices is:

$$
S(B)=\frac{A}{\bar{a}} S\left(\bar{Y}_{s t}\right)
$$

The area swept in a standard tow $(\overline{\mathrm{a}})$ is the product of the estimated distance between the wing ends $(17 \mathrm{~m})$ and the standard tow length (4 naut. miles), i.e. 0.037 $\mathrm{nm}^{2}$. No attempt has been made to estimate the catchability coefficient of the trawl.

With large number of hauls the stratified mean becomes nearly normally distributed and thus confidence intervals for the average number or weight-perhaul can be constructed using tables of normal distribution.

\section{Results}

The results presented are primarily based on the material sampled in March 1985. Material from March 1986 is included in some considerations as stated in each case. Only data relevant to the analyses are presented here. 


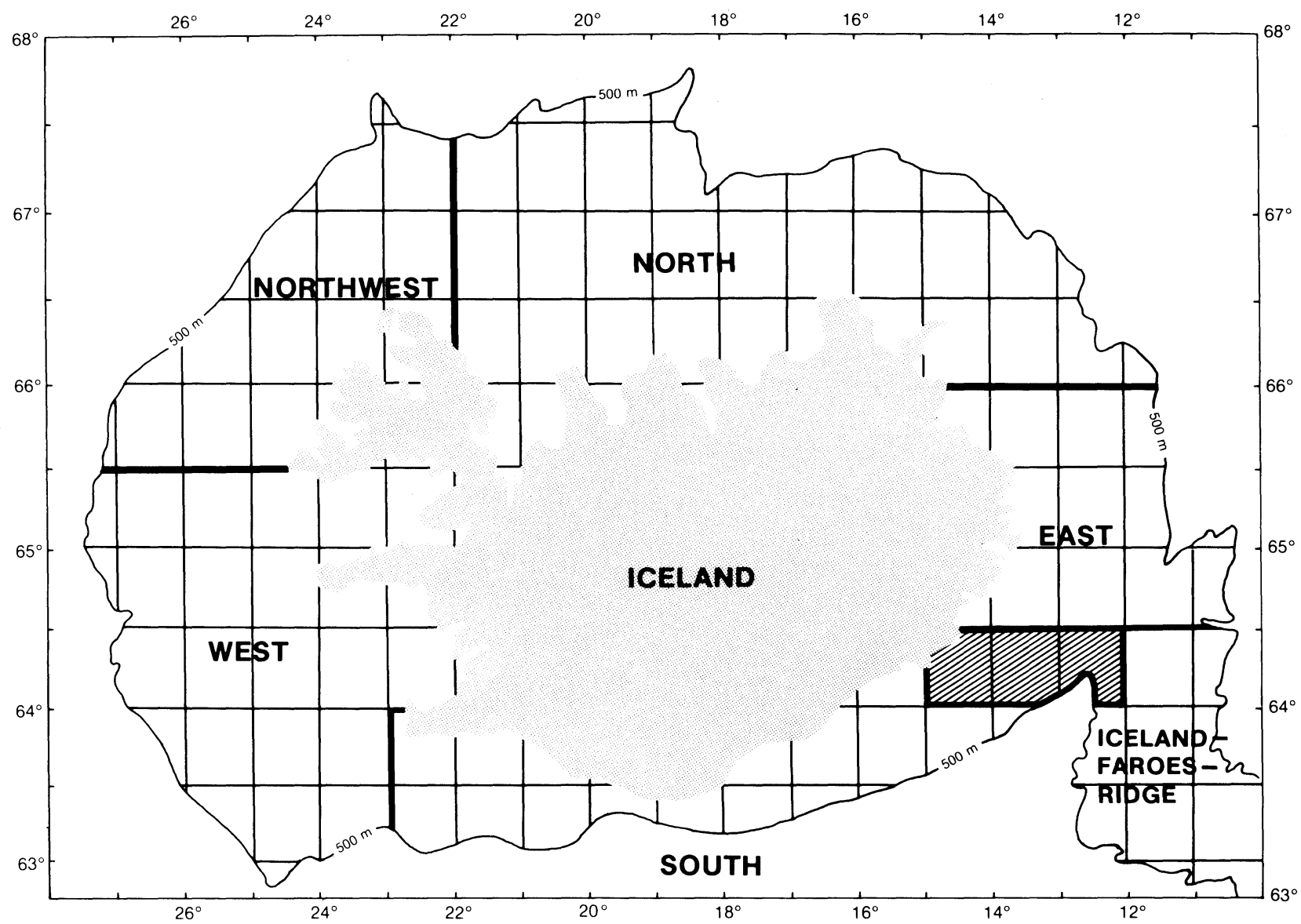

Fig. 3. The division of the survey area into hydrographic subareas. Observations from statistical units $412-414$ (shaded) are not included in the temperature values because of the highly variable hydrographic conditions of the area (boundaries of ocean current).

TABLE 4. Near-bottom, surface temperatures and standard deviations in six hydrographic subareas (Fig. 3).

\begin{tabular}{|c|c|c|c|c|c|c|}
\hline \multirow[b]{2}{*}{ Area } & \multicolumn{3}{|c|}{ Near-bottom temperatures } & \multicolumn{3}{|c|}{ Surface temperatures } \\
\hline & ${ }^{\circ} \mathrm{C}$ & $\begin{array}{l}\text { Standard } \\
\text { deviations }\end{array}$ & $\begin{array}{c}\text { Number of } \\
\text { observations }\end{array}$ & ${ }^{\circ} \mathrm{C}$ & $\begin{array}{c}\text { Standard } \\
\text { deviations }\end{array}$ & $\begin{array}{l}\text { Number of } \\
\text { observations }\end{array}$ \\
\hline South & 5.67 & 0.31 & 27 & 6.84 & 0.46 & 35 \\
\hline West & 4.47 & 0.81 & 68 & 5.95 & 0.89 & 98 \\
\hline Northwest & 4.42 & 1.58 & 125 & 5.02 & 1.19 & 135 \\
\hline North & 3.36 & 1.27 & 122 & 3.31 & 0.66 & 146 \\
\hline $\begin{array}{l}\text { East } \\
\text { Iceland- }\end{array}$ & 2.54 & 1.16 & 56 & 2.74 & 0.49 & 79 \\
\hline Faroes-Ridge & 0.72 & 1.58 & 9 & 3.33 & 2.78 & 6 \\
\hline
\end{tabular}

\section{Environmental observations}

Near-bottom temperature was measured on 435 stations. The accuracy of the measurements is expected to be $0.5^{\circ} \mathrm{C}$. Near-bottom and surface temperatures were calculated for six hydrographic subareas (Fig. 3) which, generally, are considered more or less homogeneous from a hydrographic point of view. High temperature values observed in March
1985 (Table 4) were the highest recorded for this season since observations commenced in March 1970.

The estimates of wind force and sea state demonstrate the unusually stable weather conditions which prevailed during the survey in March 1985 (Table 5). Parameters of this kind are considered potential correction factors in the case of weather related catchability. 
TABLE 5. Estimates of wind force, wave height and sea state which prevailed during the survey in March 1985.

\begin{tabular}{|c|c|c|c|c|c|c|c|}
\hline \multicolumn{4}{|c|}{ Environmental parameters } & \multicolumn{4}{|c|}{ Fishing gear parameters } \\
\hline \multicolumn{2}{|c|}{ Wind force } & \multicolumn{2}{|c|}{ Wave height } & \multicolumn{2}{|c|}{ Towing speed } & \multicolumn{2}{|c|}{ Trawl opening } \\
\hline $\begin{array}{l}\text { Beaufort } \\
\text { scale }\end{array}$ & $\begin{array}{c}\text { Frequency } \\
(\%)\end{array}$ & $(\mathrm{m})$ & $\begin{array}{l}\text { Frequency } \\
\qquad(\%)\end{array}$ & $(\mathrm{nm} / \mathrm{h})$ & $\begin{array}{l}\text { Frequency } \\
\qquad \%)\end{array}$ & $(\mathrm{m})$ & $\begin{array}{c}\text { Frequency } \\
(\%)\end{array}$ \\
\hline 0 & 10.4 & $0-0$ & 4.7 & 2.9 & 0.2 & 2.2 & 0.3 \\
\hline 1 & 7.3 & $0-0.1$ & 14.0 & 3.0 & 0.2 & 2.3 & 0.3 \\
\hline 2 & 13.6 & $0.1-0.5$ & 27.8 & 3.1 & 0.4 & 2.4 & 0.3 \\
\hline 3 & 20.5 & $0.5-1.25$ & 32.2 & 3.2 & 1.6 & 2.5 & 0.6 \\
\hline 4 & 17.1 & $1.25-2.5$ & 18.4 & 3.3 & 1.6 & 2.6 & 1.0 \\
\hline 5 & 14.7 & $2.5-4.0$ & 2.9 & 3.4 & 2.2 & 2.7 & 1.6 \\
\hline 6 & 8.6 & & & 3.5 & 2.6 & 2.8 & 1.3 \\
\hline 7 & 6.5 & & & 3.6 & 4.3 & 2.9 & 2.5 \\
\hline \multirow[t]{7}{*}{8} & 1.3 & & & 3.7 & 24.1 & 3.0 & 69.9 \\
\hline & & & & 3.8 & 33.0 & 3.1 & 2.5 \\
\hline & & & & 3.9 & 14.6 & 3.2 & 1.9 \\
\hline & & & & 4.0 & 12.1 & 3.4 & 0.3 \\
\hline & & & & 4.1 & 1.8 & 3.5 & 16.3 \\
\hline & & & & 4.2 & 1.2 & 3.6 & 0.6 \\
\hline & & & & 4.5 & 0.2 & 3.7 & 0.6 \\
\hline
\end{tabular}

\section{Mean}

3.4 (Beaufort)

$1.15 \mathrm{~m}$

$3.8 \mathrm{~nm} / \mathrm{h}$

$3.07 \mathrm{~m}$

\section{Fishing gear parameters}

At 483 stations it was possible to keep the standard towing distance of 4.0 naut. miles. In 42 cases the towing distance was slightly longer and on 70 occasions it was shorter.

The relationship between warp length and trawling depth (the scope) is not the same throughout the depth range. For depths down to approximately $200 \mathrm{~m}$ the scope was approximately $3: 1$. In deeper water relatively shorter warp lengths were used and the scope was approximately $2.5: 1$.

The towing speed was on average 3.8 knots. The vertical trawl opening, as measured on 319 stations with a Scanmar Sonde, had a mean value of $3.07 \mathrm{~m}$. The frequency distribution (Table 5) shows that openings of 3.0 and $3.5 \mathrm{~m}$ were most common. During a tow the recordings of the trawl opening tended to fluctuate considerably, which favours the selection of these "round" figures.

\section{Length distributions}

The length distributions of the six species, in both the southern and the northern areas, are shown in Fig. 4. The "juvenile" component of the cod stock $(<50 \mathrm{~cm})$ was recorded almost exclusively in the northern area. Of the remaining part of the cod stock, only fish larger than $85 \mathrm{~cm}$ were more numerous in the southern area. Thus, the cod stock proportions in the two areas differed even more than assumed in the survey planning (see section Survey design). The small haddock $(<40$ $\mathrm{cm}$ ) were also more abundant in the northern area. The remaining part of the haddock stock was mainly in the length range $45-64 \mathrm{~cm}$, and was mostly in the southern area.

The length distribution of saithe was characterized by medium sized fish in the $50-79 \mathrm{~cm}$ length range, which were mainly recorded in the southern area. The "juvenile" component of saithe $(<50 \mathrm{~cm})$ was recorded in limited numbers in the northern area along with large fish in the 75-84 cm length groups. The larger redfish $(>35 \mathrm{~cm})$ were also much more abundant in the southern area, and the smaller fish occurred more frequently in the northern area. The number of redfish smaller than $25 \mathrm{~cm}$ was, however, negligible.

The length distribution of catfish was relatively even, especially in the $30-64 \mathrm{~cm}$ length range. The fish were usually more abundant in the northern area, although the largest fish $(>65 \mathrm{~cm})$ were more abundant in the south. However, the main part of the long rough dab stock was located in the northern area, especially the larger fish. The "juvenile" part of the stock $(<25 \mathrm{~cm})$ was more evenly distributed.

In general, the distributions of the juvenile stock components of the different species were mainly confined to the northern part of the survey area. This indicates the area supports common nursery grounds and offers environmental conditions favourable to juveniles of all fish species considered.

\section{Age distributions}

The age distributions of cod, haddock, saithe and catfish are shown in Fig. 5. The distributions by numbers are illustrated with respect to the two different areas and the distributions by weight with respect to 

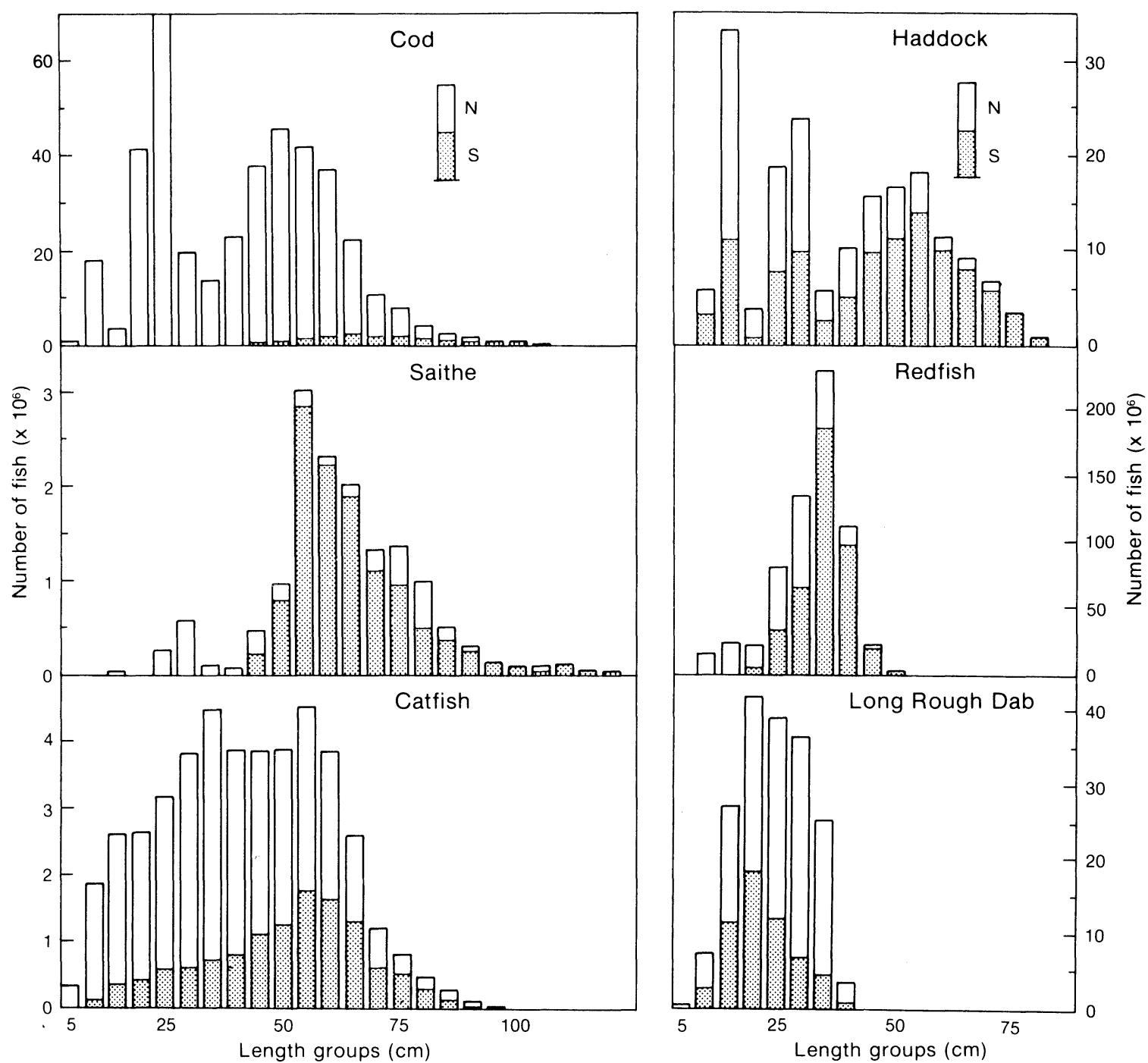

Fig. 4. The length distributions of cod, haddock, saithe, redfish, catfish and long rough dab in the northern (N) and southern (S) areas.

the maturity of the fish. In addition the mature part of each age group is divided with respect to the two areas.

Cod. The age distribution of cod by numbers shows that all age-groups, except age-group 10, were much more frequent in the northern area than in the southern one. The catchable part of the cod stock consists of 4-year-old fish and older. The age distribution by weight shows that age-group 5 dominated the catchable stock. Age-groups older than 10 years made up less than $1 \%$ of the catchable stock. The bulk of the spawning stock consisted of age-groups 5,6 and 7 , which are only partly mature. Age-groups 8-10 contributed less to the spawning stock, and older fish were recorded only occasionally. The maturing component of the stock was located mainly in the northern area and this was an unexpected result since the survey was carried out during the beginning of the spawning season.

Haddock. The age distribution of haddock by numbers shows that the juvenile age-groups (age groups 1-3) were more frequent in the northern area, whereas the catchable stock was more abundant in the southern area. The age distribution by weight shows that age-group 5 dominated in the catchable part of the stock. The spawning stock consisted almost exclusively of age-groups 4 to 9 , and was mainly located in the southern area.

Saithe. Saithe were mainly found in the southern area. The juvenile age-groups 1-3 were recorded only occasionally. The catchable part of the stock was mainly composed of age-groups 4-9. The spawning 

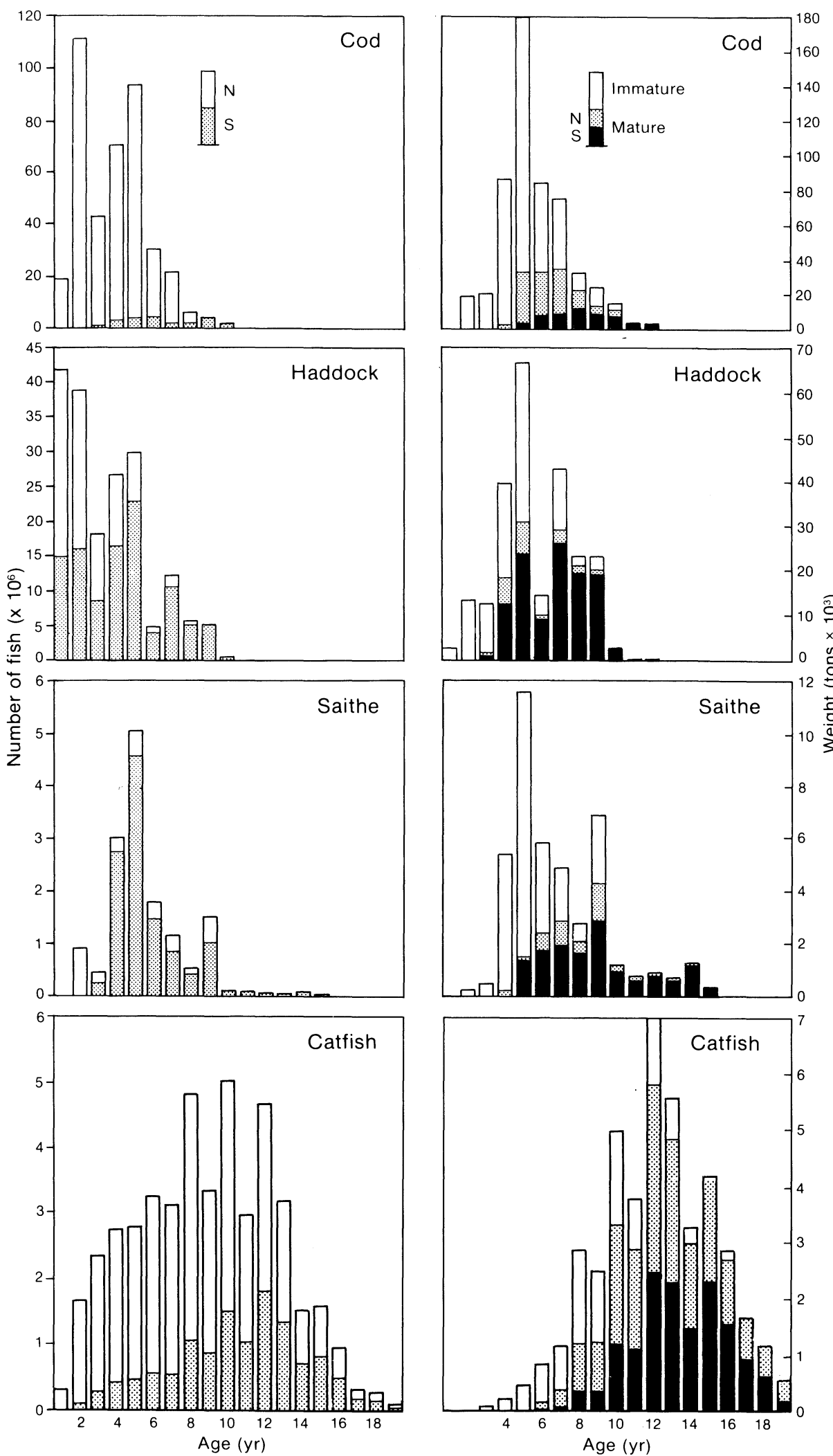

Fig. 5. The age distributions of cod, haddock, saithe and catfish with respect to areas and maturity. The mature part of each age-group is divided into northern $(\mathrm{N})$ and southern $(\mathrm{S})$ components. 
stock was made up of a wide range of age-groups of similar biomass, and it was mainly recorded in the southern area.

Catfish. Catfish were most abundant in the northern area particularly for the younger age-groups. With increasing age, however, an increasing proportion of the stock was recorded in the southern area. The abundance estimates of age-groups belonging to the juvenile part of the stock (1-7 years) were remarkably similar, suggesting a relatively stable recruitment of the stock. Catfish enter the fishery at age 8 and the commercial catch is based mainly on age-groups 10-15. The catchable component of the stock ( 8 years and older) consisted mainly of age-groups $8-16$. The bulk of the spawning stock consisted of 10-16-year-old fish. The larger part of this stock component was recorded in the northern area although a significant proportion was located in the south.

\section{Diurnal catch variations}

Diurnal catch variations of cod are known to exist in different seasons (Pálsson, MS 1984). However, these variations are considered to be less pronounced during late winter than in summer or early winter. Figure 6 shows the observed diurnal variation of the catches in March 1985 and March 1986, measured as average number of fish in a standard tow in time intervals of $4 \mathrm{hr}$. Pronounced and consistent diurnal catch variations were observed for redfish and catfish, although with different (inverse) patterns. For cod and haddock, irregular diel patterns were observed in both years. The lowest variations were recorded for long rough dab. The pattern of saithe in 1986 is the result of extreme high catches in one time interval. Underwater observations have shown that catfish tend to escape the trawl by swimming under the fishing line. This behaviour is apparently limited to the bright hours of the day.
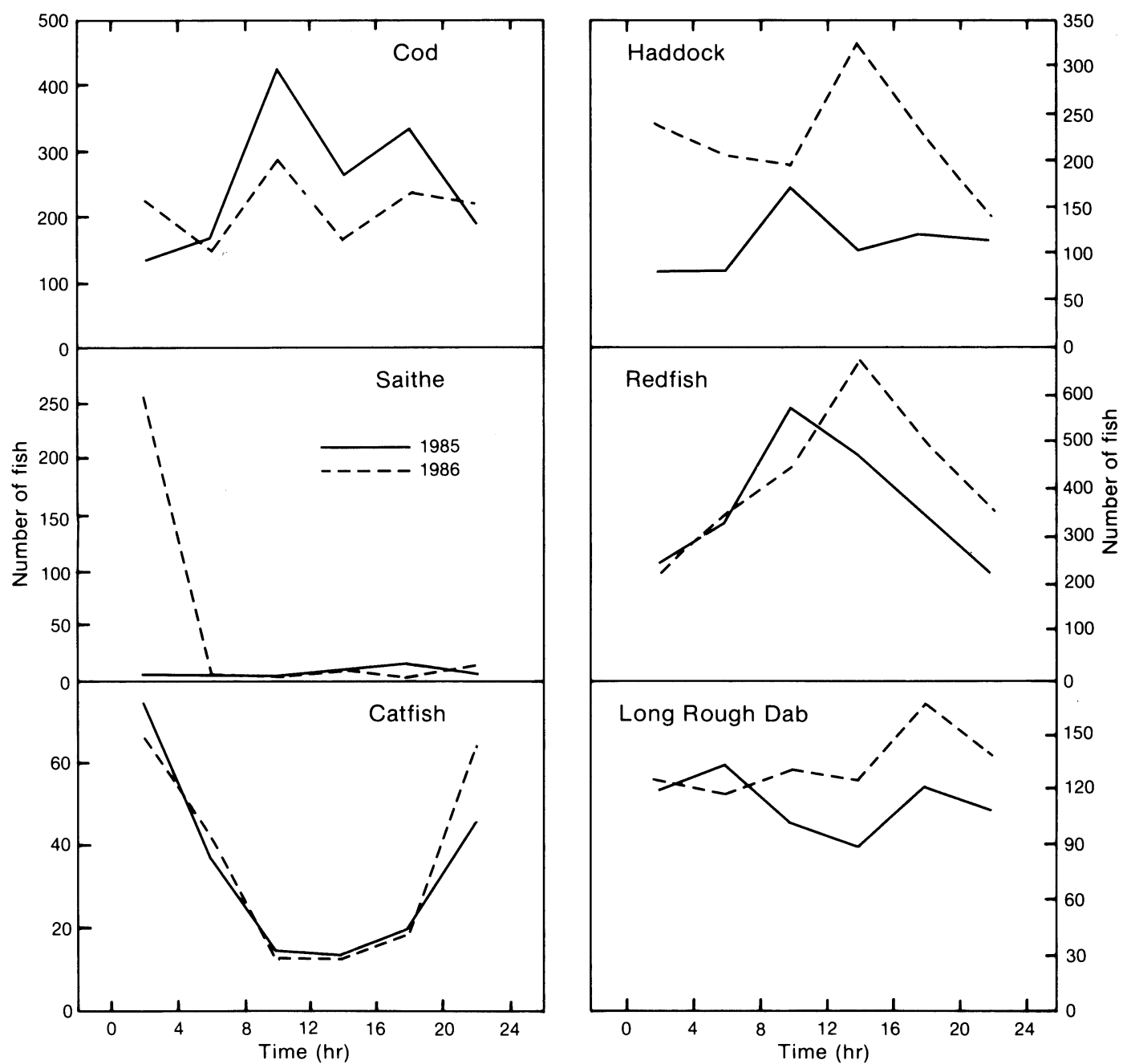

Fig. 6. Diurnal catch variations in 1985 and 1986 of cod, haddock, saithe, redfish, catfish and long rough dab in time intervals of $4 \mathrm{hr}$. Average number of fish in a standard tow. 
In considering the effect of diurnal catch variation on stratified mean catch in numbers, separate indices were calculated for day- and night-time hauls. The results are presented in Table 6 . The day-time hauls for cod were taken from $0600 \mathrm{~h}$ to $2000 \mathrm{~h}$ and for redfish and catfish from $1000 \mathrm{~h}$ to $1800 \mathrm{~h}$. For cod the day- and night-time indices in the 1985 survey differ widely with a t-value of 3.7, and the standard deviation in the daytime catches is about six times higher than at night. The same tendencies were observed in the 1986 survey although not so pronounced. The night-time indices and the standard deviations are quite similar in both years. On the other hand, the day-time indices and the standard deviation in 1985, are two or even three times higher respectively, than in 1986. This would suggest the night-time index to be a more stable index of the population density. Also, the magnitude of the difference in the day/night indices between years suggests the possibility of a change in catchability which could be a source of bias.

For redfish the day-time index in both years is about $70-80 \%$ higher than the night time index, and there is a correspondingly lower standard deviation in the night-time catches. On the other hand, the catfish indices are about three times higher from the nighthauls with t-values of 5.5 and 6.6 .

TABLE 6. Stratified mean catch in numbers per standard tow in day and night-time hauls for cod, redfish and catfish and the corresponding t-test values during 1985 and 1986

\begin{tabular}{|c|c|c|c|c|c|c|}
\hline & \multicolumn{3}{|c|}{1985 Survey } & \multicolumn{3}{|c|}{1986 Survey } \\
\hline & Total & Day & Night & Total & Day & Night \\
\hline \multicolumn{7}{|c|}{ Cod } \\
\hline$\overline{\mathrm{Y}}_{\mathrm{st}}$ & 244 & 387 & 131 & 179 & 197 & 165 \\
\hline Standard error & 44 & 68 & 13 & 14 & 23 & 15 \\
\hline$V_{r}$ & 18 & 18 & 10 & 8 & 12 & 9 \\
\hline Standard deviations & 1,122 & 1,253 & 207 & 339 & 420 & 238 \\
\hline No. of stations & 595 & 340 & 255 & 586 & 334 & 252 \\
\hline & \multicolumn{3}{|c|}{$\mathrm{t}=3.7$} & \multicolumn{3}{|c|}{$t=1.1$} \\
\hline \multicolumn{7}{|c|}{ Redfish } \\
\hline $\bar{Y}_{\text {st }}$ & 390 & 596 & 329 & 437 & 599 & 348 \\
\hline Standard error & 45 & 111 & 45 & 54 & 123 & 49 \\
\hline$V_{1}$ & 9 & 19 & 14 & 12 & 21 & 14 \\
\hline Standard deviations & 1,098 & 1,530 & 905 & 1,307 & 1,726 & 966 \\
\hline No. of stations & 595 & 190 & 405 & 586 & 197 & 389 \\
\hline & \multicolumn{3}{|c|}{$t=2.2$} & \multicolumn{3}{|c|}{$t=1.9$} \\
\hline \multicolumn{7}{|c|}{ Catfish } \\
\hline $\bar{Y}_{\text {st }}$ & 27 & 11 & 34 & 28 & 11 & 37 \\
\hline Standard error & 2.8 & 1.7 & 4.0 & 2.6 & 1.7 & 3.8 \\
\hline$V_{r}$ & 10 & 15 & 12 & 9 & 16 & 10 \\
\hline Standard deviations & 68 & 23 & 80 & 63 & 24 & 75 \\
\hline No. of stations & 595 & 190 & 405 & 586 & 197 & 389 \\
\hline & \multicolumn{3}{|c|}{$\mathrm{t}=5.5$} & \multicolumn{3}{|c|}{$t=6.6$} \\
\hline
\end{tabular}

\section{Stock size indices}

For each species the calculated total biomass index based on both random and non-random hauls, spawing stock index and stratified mean catch-perstandard-tow are given in Table 7 with respect to areas, for 1985 and 1986 surveys. The standard errors of total biomass and stratified mean catch are also given. Age disaggregated VPA and survey data for cod, haddock and saithe are given in Table 8 and plotted in Fig. 7 .

Cod. The total biomass index for cod was 556,000 tons in 1985 and 394,000 tons in 1986. The standard error was $16 \%$ in 1985 and $9 \%$ in 1986 . The total spawning stock biomass index was 157,000 tons in 1985 and 128,000 tons in 1986. Comparison between VPA and survey indices in numbers-by-age shows high correlation for age-groups 4 and older in 1985 and 1986. In both years the intercept of the relationship with the $y$-axis is not significantly different from zero. Thus, it can be concluded that 4-year-old cod are more or less fully recruited to the survey.

The ratio of the survey to VPA estimates for age 4+ cod was much lower in 1986 than 1985 suggesting increased catchability of cod in 1985 . The change in catchability may be caused by changes in behaviour due to different environmental circumstances in those 2 years. However, it should also be noted that the VPA results for the most recent years have not yet stabilized.

Haddock. The total estimated biomass index of haddock was 244,000 tons in 1985 with a standard error of $23 \%$. In contrast to cod the bulk of the biomass $(78 \%)$ was distributed on the grounds off the southern and western coast and only $23 \%$ in the colder waters off the north and east coasts. In 1986 the total biomass was estimated to be 255,000 tons and the standard error was down to $9 \%$.

Due to the large trawl mesh $(155 \mathrm{~mm})$ in use at Iceland, the catch in numbers of 3-year-old haddock is negligible. Therefore, comparison between VPA and survey indices is given for 4 year and older haddock. As for cod, these values are highly correlated and the intercept with the $y$-axis is not significantly different from zero. It seems, however, that the availability of older haddock has been somewhat lower in the latter survey compared to the VPA results.

Saithe. The 1985 total biomass index for saithe was only 44,000 tons and $42 \%$ of this biomass was mature fish. In 1986 the total biomass index was 122,000 tons, but the estimated spawning biomass index was only 16,000 tons. The standard error of the mean was relatively high in 1985 (27\%) and extremely high in 1986 $(82 \%)$. The relationship between VPA and survey indi- 
TABLE 7. Trawl survey indices of stock sizes in 1985 and 1986 in the northern (N) and the southern (S) areas and in the survey area as a whole $(\mathrm{N}+\mathrm{S})$. Total biomass index in tons and its standard error in tons and as a percentage. Spawning biomass index in tons and its proportion (\%) of the total biomass index. Stratified mean catch per standard tow in numbers and its standard error in numbers and as a percentage.

\begin{tabular}{|c|c|c|c|c|c|c|c|c|c|}
\hline \multirow[b]{3}{*}{ Species } & \multirow[b]{3}{*}{ Area } & \multicolumn{3}{|c|}{ Total biomass } & \multicolumn{2}{|c|}{ Spawning biomass } & \multicolumn{3}{|c|}{ Stratified mean catch } \\
\hline & & \multirow[b]{2}{*}{ (tons) } & \multicolumn{2}{|c|}{$\begin{array}{l}\text { Standard } \\
\text { error }\end{array}$} & \multirow[b]{2}{*}{ (tons) } & \multirow[b]{2}{*}{$(\%)$} & \multirow[b]{2}{*}{ (No.) } & \multicolumn{2}{|c|}{$\begin{array}{c}\text { Standard } \\
\text { error }\end{array}$} \\
\hline & & & (tons) & $(\%)$ & & & & (No.) & $(\%)$ \\
\hline \multicolumn{10}{|c|}{1985 Survey } \\
\hline \multirow[t]{3}{*}{ Cod } & $\mathrm{N}$ & 464 & 87 & 19 & 111 & 24 & 418 & 78 & 19 \\
\hline & $S$ & 92 & 20 & 22 & 61 & 66 & 28 & 5 & 18 \\
\hline & $N+S$ & 556 & 89 & 16 & 157 & 28 & 244 & 44 & 18 \\
\hline \multirow[t]{3}{*}{ Haddock } & $\mathrm{N}$ & 54 & 6 & 11 & 22 & 40 & 86 & 13 & 15 \\
\hline & $S$ & 190 & 57 & 30 & 117 & 62 & 142 & 29 & 20 \\
\hline & $N+S$ & 244 & 57 & 23 & 139 & 57 & 111 & 15 & 14 \\
\hline \multirow[t]{3}{*}{ Saithe } & $\mathrm{N}$ & 9 & 2 & 20 & 5 & 54 & 4 & 6 & 15 \\
\hline & $\mathrm{S}$ & 35 & 12 & 34 & 14 & 40 & 16 & 7 & 44 \\
\hline & $N+S$ & 44 & 12 & 27 & 19 & 42 & 9 & 3 & 33 \\
\hline \multirow[t]{3}{*}{ Redfish } & $N$ & 104 & 15 & 14 & & & 253 & 27 & 11 \\
\hline & $\mathrm{S}$ & 325 & 53 & 16 & & & 560 & 95 & 17 \\
\hline & $N+S$ & 429 & 55 & 13 & & & 390 & 45 & 12 \\
\hline \multirow[t]{3}{*}{ Catfish } & $N$ & 25 & 3 & 12 & 18 & 71 & 35 & 4 & 11 \\
\hline & $S$ & 17 & 5 & 29 & 14 & 82 & 17 & 4 & 24 \\
\hline & $N+S$ & 43 & 6 & 14 & 32 & 76 & 27 & 3 & 11 \\
\hline \multirow{3}{*}{$\begin{array}{l}\text { Long rough } \\
\text { dab }\end{array}$} & $\mathrm{N}$ & 37 & 3 & 8 & & & 137 & 10 & 7 \\
\hline & $S$ & 13 & 2 & 14 & & & 79 & 10 & 13 \\
\hline & $N+S$ & 49 & 3 & 6 & & & 111 & 7 & 6 \\
\hline \multicolumn{10}{|c|}{1986 Survey } \\
\hline \multirow[t]{3}{*}{ Cod } & $N$ & 318 & 29 & 9 & 71 & 22 & 300 & 24 & 8 \\
\hline & $S$ & 76 & 17 & 22 & 57 & 74 & 29 & 7 & 24 \\
\hline & $N+S$ & 394 & 34 & 9 & 128 & 28 & 179 & 14 & 8 \\
\hline \multirow[t]{3}{*}{ Haddock } & $\mathrm{N}$ & 88 & 13 & 15 & 15 & 17 & 175 & 31 & 18 \\
\hline & $S$ & 167 & 18 & 11 & 103 & 61 & 289 & 48 & 17 \\
\hline & $N+S$ & 255 & 23 & 9 & 119 & 57 & 226 & 27 & 12 \\
\hline \multirow[t]{3}{*}{ Saithe } & $N$ & 5 & 2 & 40 & 2 & 39 & 4 & 1 & 25 \\
\hline & $S$ & 117 & 100 & 85 & 14 & 12 & 107 & 100 & 93 \\
\hline & $N+S$ & 122 & 100 & 82 & 16 & 13 & 50 & 45 & 90 \\
\hline \multirow[t]{3}{*}{ Redfish } & $N$ & 125 & 19 & 15 & & & 289 & 33 & 11 \\
\hline & $S$ & 356 & 63 & 18 & & & 621 & 113 & 18 \\
\hline & $N+S$ & 480 & 66 & 14 & & & 437 & 54 & 12 \\
\hline \multirow[t]{3}{*}{ Catfish } & $N$ & 26 & 4 & 15 & & & 40 & 4 & 10 \\
\hline & $S$ & 10 & 2 & 20 & & & 13 & 2 & 15 \\
\hline & $N+S$ & 36 & 4 & 11 & & & 28 & 3 & 11 \\
\hline Long rough & $N$ & 48 & 4 & 8 & & & 173 & 16 & 9 \\
\hline dab & $\mathrm{S}$ & 15 & 3 & 20 & & & 83 & 13 & 16 \\
\hline & $N+S$ & 62 & 5 & 8 & & & 132 & 10 & 8 \\
\hline
\end{tabular}

ces show a good correlation for age-groups 5 and older i.e. spawning fish, and the intercept is not significantly different from zero. However, the survey spawning biomass indices are only $9-13 \%$ of VPA spawning biomass.
Redfish. This species was the most abundant in terms of numbers during both surveys. In 1985 the total biomass index was 429,000 tons and in 1986 it increased to 480,000 tons. The corresponding standard 
TABLE 8. Stock estimates of cod, haddock and saithe in numbers $\left(+10^{6}\right)$ by age in 1985 and 1986 from VPA and the Icelandic Groundfish Survey.

\begin{tabular}{|c|c|c|c|c|}
\hline \multirow{2}{*}{$\begin{array}{l}\text { Age- } \\
\text { group }\end{array}$} & \multicolumn{2}{|c|}{1985} & \multicolumn{2}{|c|}{1986} \\
\hline & VPA & Survey & VPA & Survey \\
\hline \multicolumn{5}{|c|}{ Cod } \\
\hline 4 & 134 & 79 & 96 & 28 \\
\hline 5 & 130 & 88 & 87 & 26 \\
\hline 6 & 49 & 31 & 75 & 34 \\
\hline 7 & 18 & 18 & 24 & 9 \\
\hline 8 & 7 & 6 & 7 & 3 \\
\hline 9 & 4 & 4 & 2 & 1 \\
\hline 10 & 2 & 2 & 1 & 1 \\
\hline 11 & 1 & 0.3 & 1 & + \\
\hline \multicolumn{5}{|c|}{ Haddock } \\
\hline 4 & 34 & 23 & 30 & 16 \\
\hline 5 & 27 & 30 & 24 & 18 \\
\hline 6 & 2 & 3 & 17 & 13 \\
\hline 7 & 6 & 12 & 1 & 1 \\
\hline 8 & 7 & 4 & 3 & 3 \\
\hline \multicolumn{5}{|c|}{ Saithe } \\
\hline 5 & 23 & 5 & 28 & 13 \\
\hline 6 & 7 & 2 & 16 & 4 \\
\hline 7 & 5 & 1 & 4 & 0.7 \\
\hline 8 & 4 & 1 & 2 & 0.3 \\
\hline 9 & 4 & 2 & 2 & 0.2 \\
\hline 10 & 2 & 0.1 & 2 & 0.3 \\
\hline
\end{tabular}

errors were 13 and $14 \%$. As the redfish in Icelandic waters is regarded to be a part of the redfish stock complex in the East Greenland-Iceland-Faroe area, comparison of these indices to VPA biomass from a joint assessment in this area is difficult.

Catfish. The total biomass index for catfish was 43,000 tons in 1985 and 36,000 tons in 1986 with standard errors of 14 and $11 \%$ respectively. At present, there is no VPA available for this stock.

Long rough dab. Long rough dab has not been commercially exploited in Icelandic waters. Compared to the results of the commercially more important species given above, the total biomass indices for long rough dab of 49,000 tons in 1985 and 62,000 tons in 1986 , indicate that this resource may have some fishing potential. The standard errors of 6 and $8 \%$ were the lowest recorded in the surveys.

\section{Random and non-random indices}

A comparison of random abundance indices and the non-random indices is shown in Fig. 8 for the northern and the southern areas respectively. The indices for cod, haddock and catfish are given with respect to age and the index for redfish with respect to length.
In the northern area (Fig. 8A), the non-random indices of cod are usually higher, especially for ages 4 and 5 . The random index for age-group 2, however, is much higher than the non-random one. For haddock the random index is considerably higher for the younger age-groups, whereas for age-group 6 and older the non-random index becomes higher. For catfish and redfish the non-random index is slightly higher than the random index over the largest part of the age or length range.

For cod in the southern area (Fig. 8B), the nonrandom abundance index was roughly two or three times higher than the random index for age 4 and older. For haddock the non-random index was also higher in most age-groups. For catfish the random indices were somewhat higher for age-group 9 and younger, whereas for the older age-groups the non-random indices became increasingly larger than the random ones. For redfish in the southern area, the non-random indices were somewhat higher except in length groups 35-39 $\mathrm{cm}$ and $40-44 \mathrm{~cm}$ in which the redfish were most abundant.

In general, and particularly for age-groups 4+ cod and haddock, the non-random abundance indices, based on the trawling stations selected by fishermen, were higher than the random indices. The difference seems to be most pronounced for cod, which should be expected since non-random stations were selected with respect to the assumed highest abundance of cod. However, the random indices were substantially higher for juvenile cod (age-group 2) and the younger agegroups of haddock in the northern area. This seems reasonable since fishermen were inclined to select their stations with respect to the catchable component of the stock.

A comparison of the aggregated stratified mean catch of cod, haddock, catfish and redfish, in the two surveys, in numbers and weight per standard tow from stations selected non-randomly by fishermen and random selected stations, are presented in Table 9, as well as corresponding t-values. The observed general trend is that the indices from the non-random stations are somewhat higher. However, according to the two tailed t-test, the indices are not significantly different except for cod in the southern area in both weight and numbers, and for haddock (in numbers) in the northern area in the 1985 survey.

No attempt was made to perform any statistical tests on the age data as these were calculated using age-length keys. On the other hand, chi-square tests were used on the length distributions in numbers of cod, haddock, catfish and redfish (Table 10) and the results in all cases was that, the observed differences were highly significant. 

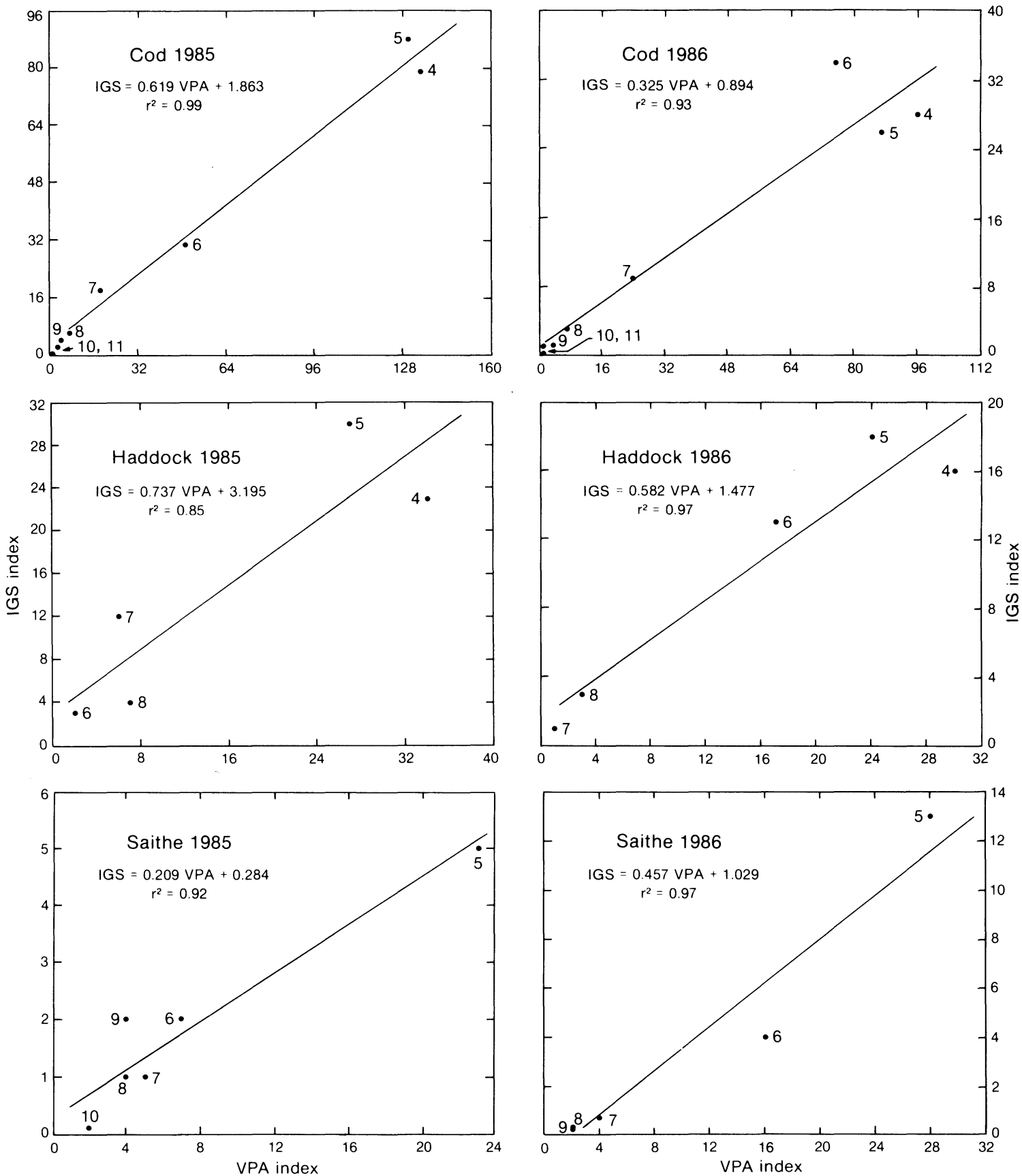

Fig. 7. The relationships between age disaggregated virtual population analysis (VPA) and Icelandic Groundfish Survey (IGS) indices for cod, haddock and saithe in 1985 and 1986. Age groups are indicated.

Thus, the differences in the aggregated indices seem to depend on the age composition of the stock and different selection patterns in the non-random and random stations. Which of the indices, non-random, random or pooled, give the best estimate of population densities can only be determined through comparison with other abundance estimates in longer time series.

\section{Discussion}

In this survey design the allocation of stations to strata and statistical squares is based on a pre-survey cod density evaluation. This evaluation can be compared with the actual density of cod recorded in each square during the two surveys (Fig. 9). The median of 

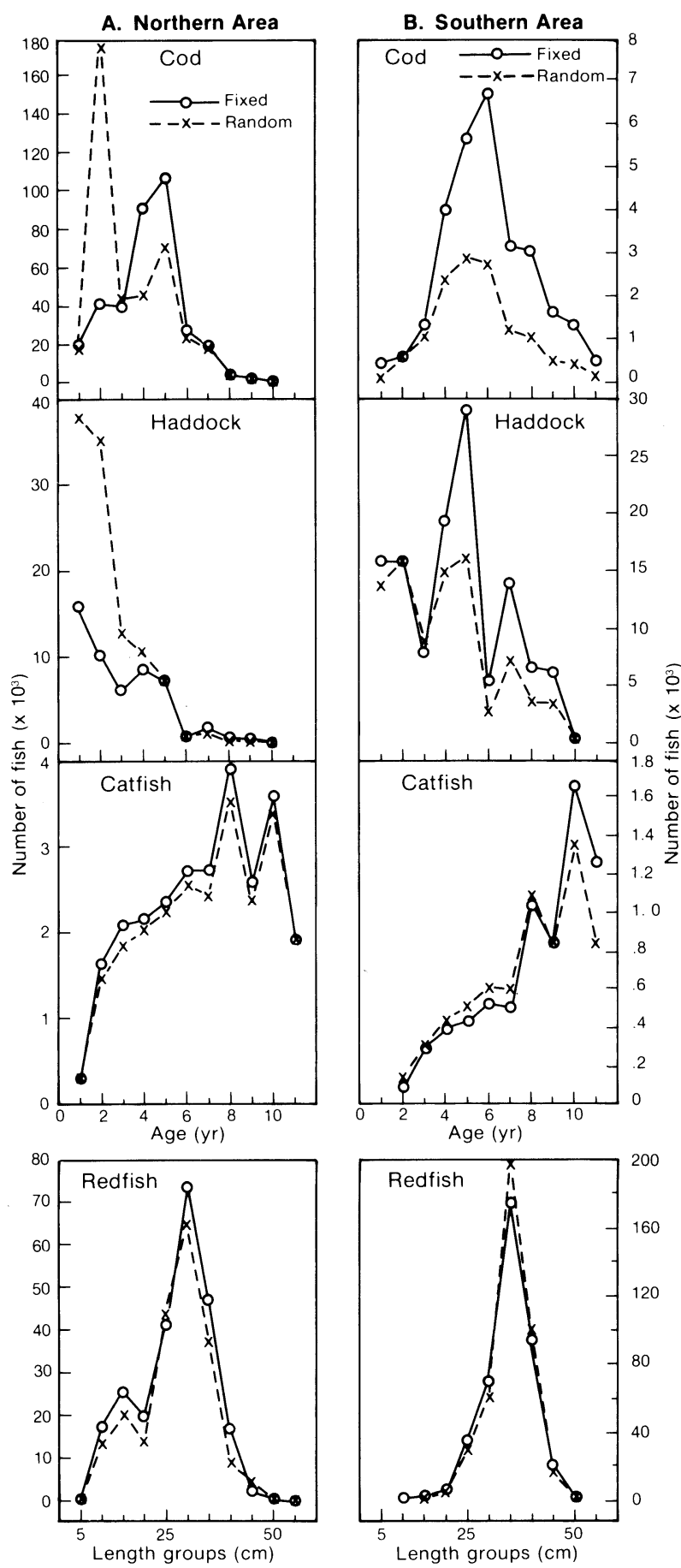

Fig. 8. Random and non-random stock size indices in 1985 of cod haddock, catfish and redfish in the northern and southern areas. Calculated as number of fish by age or length group.

the observed density appears to be the most appropriate measure for data of this kind.

In the southern area the correlation between presurvey evaluation and observed density of cod is, in general, fairly acceptable although extreme values are observed, mainly in the second highest evaluation category. In the northern area an increasing trend in the median is observed for the first four categories, but median values decline in the two highest categories. The highest observed density values are mainly found in the second, third and fourth category. Clearly, a revision of the pre-survey evaluation in the northern area is needed.

The gain in precision of the 1985 and 1986 surveys over that of the earlier surveys was generally consistent with expectations, and is illustrated in Fig. 10 with a plot of the relative standard error $\left(V_{r}\right)$ for the individual survey stratified means, superimposed on the calculated relationship of $V_{r}$ versus sample size as described in the Methods section. The relative standard error values were $V_{r}=17.6 \%$ in 1985 and $7.6 \%$ in 1986, as compared with an average value $\bar{V}_{r}=21.6 \%$ for the 1982-84 surveys. The relatively high variance in the 1985 survey coincides with abnormally good weather conditions, strong recruiting year-classes and patchy distribution pattern of cod. Further surveys are obviously necessary for a more definite evaluation of the actual gain in precision.

Although this survey was mainly designed to reduce as much as possible the variance in the abundance estimation of cod, it is interesting to note that for some other species equally low or even lower relative standard errors were observed in the abundance indices. The values of the standard error in 1985 and 1986 were 13 and $14 \%$ for redfish, 14 and $11 \%$ for catfish and 6 and $8 \%$ for long rough dab respectively. Somewhat higher values were recorded for haddock (23 and $9 \%$ ), and the highest ones for saithe (27 and $82 \%$ ). The relatively low standard error values for long rough dab, redfish and catfish suggest that the biomass indices may be of sufficient precision for tracking their abundance trends in coming years.

Groundfish surveys have been conducted on various fishing grounds in the North Atlantic Ocean during the last decade. A comparison of the precision achieved on five surveys is compiled in Table 11 (Grosslein, 1971; Schopka et al., MS 1983; Brodie and Wells, MS 1985; Cornus, MS 1985; Mabeau et al., MS 1986). In all surveys, except on Georges Bank, a pronounced interannual variability in precision is evident. This indicates variable catchability as a common factor of particular significance in Arctic and Sub-Arctic regions.

The Icelandic survey has achieved the greatest precision, which primarily is a result of increased sampling effort (10 stations per $1,000 \mathrm{~nm}^{2}$ ). Comparable precision values have been achieved on the Flemish Cap, where the sampling effort has been of the same order. Thus, an effort of the order of 10 stations $/ 1,000$ $\mathrm{nm}^{2}$ appears to be the minimum sampling required to achieve precision values below 0.10 . 
TABLE 9. Stratified mean catch in numbers and weight of random (R) and non-random (NR) selected stations in 1985 and 1986, and corresponding t-values.

\begin{tabular}{|c|c|c|c|c|c|c|c|c|c|c|c|c|}
\hline \multirow[b]{3}{*}{ Species } & \multicolumn{6}{|c|}{1985} & \multicolumn{6}{|c|}{1986} \\
\hline & \multicolumn{3}{|c|}{ Northern area } & \multicolumn{3}{|c|}{ Southern area } & \multicolumn{3}{|c|}{ Northern area } & \multicolumn{3}{|c|}{ Southern area } \\
\hline & NR & $\mathrm{R}$ & $\mathrm{t}$ & NR & $\mathrm{R}$ & $\mathrm{t}$ & NR & $\mathrm{R}$ & $\mathrm{t}$ & NR & $\mathrm{R}$ & $\mathrm{t}$ \\
\hline \multicolumn{13}{|c|}{ Indices in numbers } \\
\hline Cod & 389 & 443 & 0.4 & 39 & 18 & $-2.0^{\mathrm{a}}$ & 326 & 275 & -1.2 & 22 & 35 & 0.9 \\
\hline Haddock & 57 & 116 & $2.3^{\mathrm{a}}$ & 164 & 119 & -0.8 & 181 & 170 & -0.2 & 328 & 250 & -0.8 \\
\hline Catfish & 36 & 35 & -0.2 & 19 & 15 & -0.5 & 47 & 33 & -1.5 & 13 & 13 & -0.8 \\
\hline Redfish & 279 & 229 & -0.9 & 560 & 569 & 0.1 & 348 & 230 & -1.8 & 627 & 602 & -0.1 \\
\hline \multicolumn{13}{|c|}{ Indices in weight } \\
\hline Cod & 551 & 455 & -0.5 & 182 & 68 & $-2.1^{\mathrm{a}}$ & 378 & 314 & -1.0 & 82 & 124 & 0.9 \\
\hline Haddock & 53 & 64 & 0.8 & 321 & 190 & -0.8 & 108 & 83 & -0.9 & 231 & 218 & -0.2 \\
\hline Catfish & 27 & 28 & 0.1 & 30 & 18 & 0.9 & 2 & 29 & 0.1 & 15 & 12 & 0.9 \\
\hline Redfish & 125 & 103 & -0.7 & 434 & 450 & 0.1 & 168 & 102 & -1.6 & 503 & & \\
\hline Redfish & 125 & 103 & -0.7 & 434 & 450 & 0.1 & 168 & 102 & -1.6 & 503 & 444 & -0.3 \\
\hline No. of stations & 211 & 210 & & 88 & 86 & & 211 & 202 & & 89 & 84 & \\
\hline
\end{tabular}

a significantly different

TABLE 10. Comparison of length distributions in numbers from random and non-random stations in 1985 and 1986 (chi-square values and probabilities).

\begin{tabular}{|c|c|c|c|c|c|c|c|c|c|c|c|c|}
\hline \multirow[b]{3}{*}{ Species } & \multicolumn{6}{|c|}{1985} & \multicolumn{6}{|c|}{1986} \\
\hline & \multicolumn{3}{|c|}{ Northern area } & \multicolumn{3}{|c|}{ Southern area } & \multicolumn{3}{|c|}{ Northern area } & \multicolumn{3}{|c|}{ Southern area } \\
\hline & $x^{2}$ & d.f. & $p$ & $x^{2}$ & d.f. & $\mathrm{p}$ & $x^{2}$ & d.f. & $\mathrm{p}$ & $\overline{x^{2}}$ & d.f. & p. \\
\hline Cod & 12032 & 19 & $<0.0001$ & 219 & 21 & $<0.0001$ & 581 & 22 & $<0.0001$ & 252 & 21 & $<0.0001$ \\
\hline Haddock & 1387 & 13 & $<0.0001$ & 322 & 13 & $<0.0001$ & 1994 & 13 & $<0.0001$ & 1530 & 13 & $<0.0001$ \\
\hline Catfish & 46 & 17 & 0.0002 & 94 & 16 & $<0.0001$ & 399 & 17 & 0.0002 & 55 & 17 & $<0.0001$ \\
\hline Redfish & 251 & 10 & $<0.0001$ & 72 & 10 & $<0.0001$ & 106 & 10 & $<0.0001$ & 102 & 10 & $<0.0001$ \\
\hline
\end{tabular}

In looking at the effect of different poststratification schemes on the stratified mean catch in numbers of cod and its standard error, the stations from the northern area in the 1986 survey were used. The following seven stratification schemes were considered:

(1) The area was divided into four adjacent strata using common knowledge about cod density and hydrography in the area;

(2) No stratification;

(3) The area was divided into seven strata based on catch per unit of effort (CPUE) data from commercial trawlers in March 1986;

(4) Same as (1) but six strata instead of four;

(5) The area was divided into three adjacent subareas and each subarea into three strata according to depth;

(6) The area was divided into seven strata based on distributional pattern in the 1985 survey;

(7) Each statistical unit as a stratum, 63 strata.

According to the results (Table 12) there seems to be no potential gain in using any of the stratified sample means in the northern area, except for (7) where the number of stations in each stratum is too low for assumption of normality. The aim of the stratification was to get a more efficient estimator of the population density in the sense of having smaller variance. These results indicate that the strata means do not differ widely and that the within strata variation is relatively high in all cases. However, the north-south stratification appears to have its effect in that the stratified mean for the entire survey $\left(\overline{\mathrm{Y}}_{\mathrm{st}}=179\right.$, see Table 6$)$ differs considerably from the nonstratified estimate (arithmetic mean $=211.8$; Steinarsson and Stefansson, MS 1986, p. 13). The effect on the standard errors is nil since these are $7.8 \%$ for the stratified as well as the non-stratified estimate. 


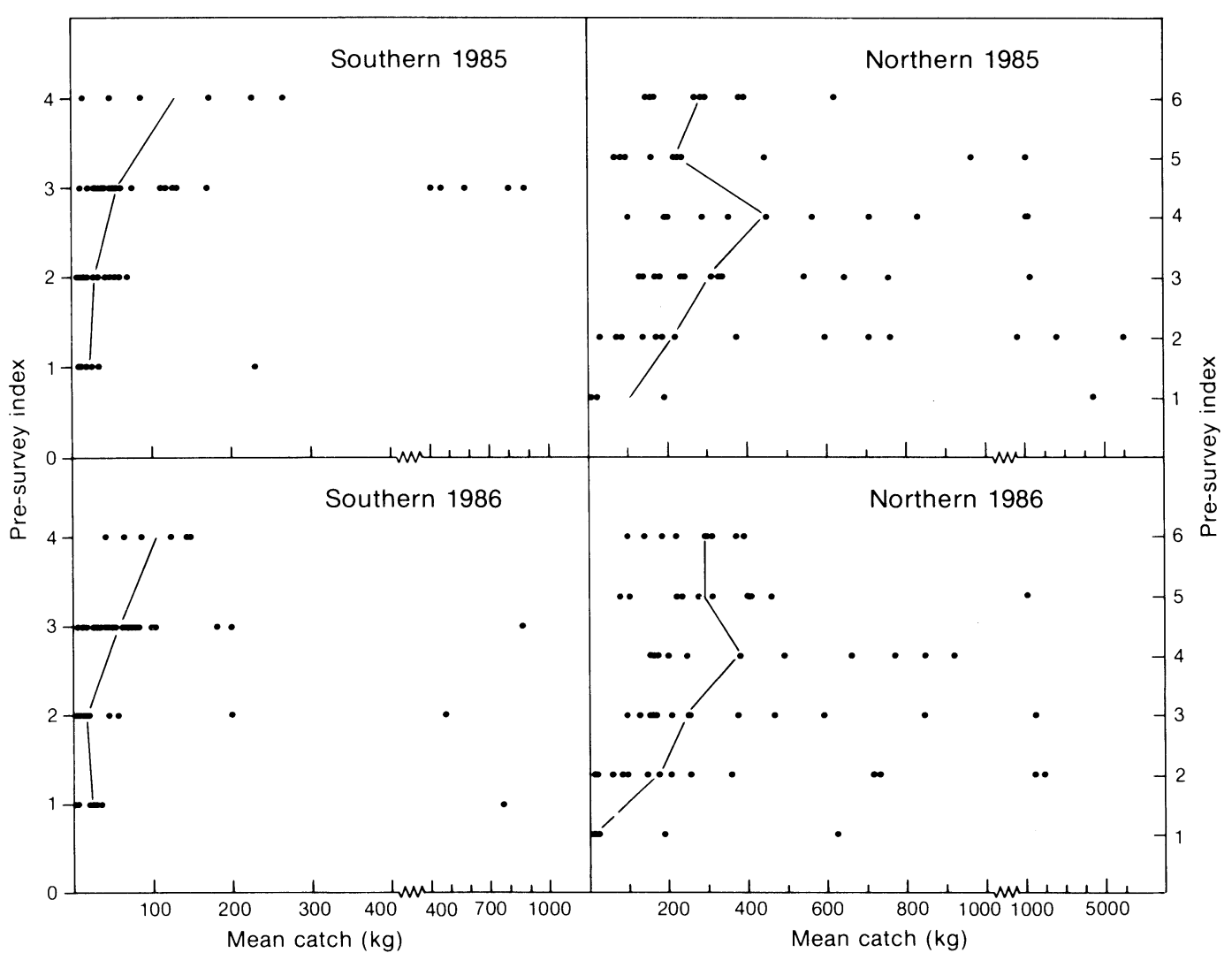

Fig. 9. Pre-survey abundance indices and observed mean catch of cod in standard tows in statistical squares in the northern and southern areas for 1985 and 1986. The median is indicated by a solid line.

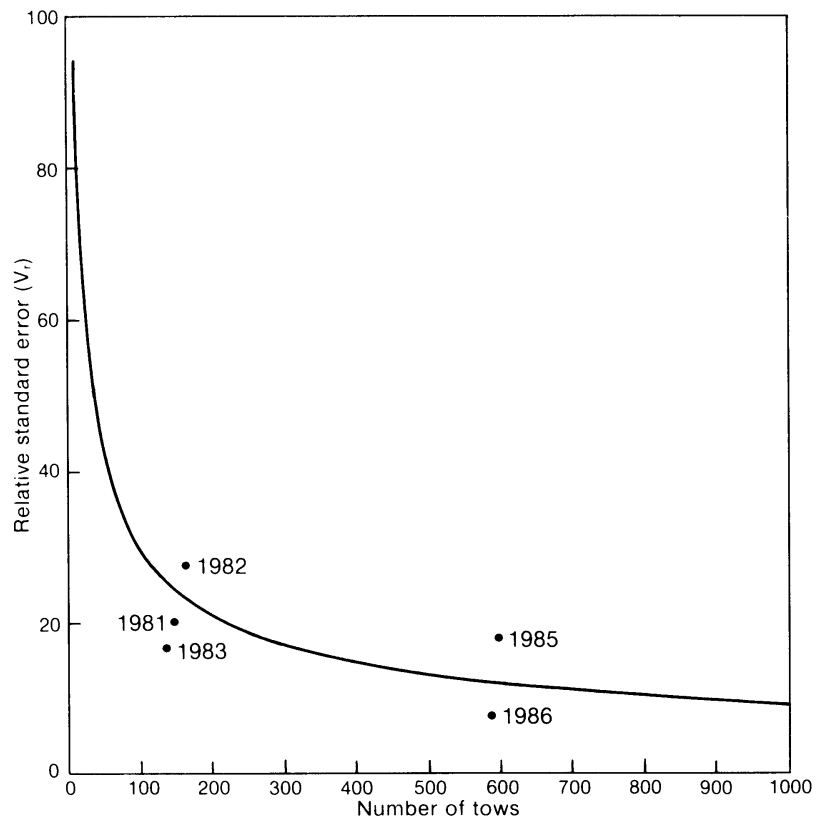

Fig. 10. The relationship of calculated and empirical values between precision (relative standard error, $V_{r}$ ) and number of tows. The solid line is calculated based on the $1982-84$ surveys.
As in any groundfish survey, there is always the potential of a difference between skippers (or vessels), although these have been eliminated as much as possible. As long as the same skippers are involved, and the relative biomass in each region is fairly constant, this will introduce the same bias every year. Note that a variation in catchability between skippers has the same effect as variation in catchability between regions. The latter is known to be present but cannot be handled.

The overall index $\left(\overline{\mathrm{Y}}_{\mathrm{st}}\right)$ is essentially a weighted average of the indices $\left(\bar{Y}_{r}\right)$, obtained from each skipper. Ideally, each of these bears a constant relationship to the underlying biomass $\left(B_{r}\right)$ in the corresponding region, that is:

$$
\bar{Y}_{r}=\alpha_{r} B_{r}
$$

If a change in biomass is reflected in the same proportion in all regions, then the same relative change will be observed in all the indices and thus also in the overall index. Therefore, the relationship between $\bar{Y}_{\text {st }}$ and $B_{\text {st }}$ is not affected by a uniform change in biomass over all regions. It is therefore not appropriate to speak 
TABLE 11. Comparison of precision and effort of groundfish surveys in Icelandic waters in March and surveys in the Northwest Atlantic. Standard error/mean catch per tow in weight, and number per tow (bold type). (Iceland, approximate area of survey $=61,000 \mathrm{~nm}^{2}$ and $135-595$ tows; Georges Bank, approximate area of survey $=15,000 \mathrm{~nm}^{2}$ and 57-70 tows; Flemish Cap, approximate area of survey = 9,000 $\mathrm{nm}^{2}$ and 79-122 tows; East Greenland, approximate area of survey $=17,000 \mathrm{~nm}^{2}$ and $36-122$ tows; Newfoundland (NAFO Subdivision 3Ps), approximate area of survey $=2,500 \mathrm{~nm}^{2}$ and 40-88 tows.)

\begin{tabular}{|c|c|c|c|c|c|c|c|c|}
\hline \multicolumn{7}{|c|}{ Cod } & \multicolumn{2}{|c|}{ Haddock } \\
\hline Year & $\begin{array}{c}\text { Georges } \\
\text { Bank }\end{array}$ & $\begin{array}{l}\text { Flemish } \\
\text { Cap }\end{array}$ & $\begin{array}{c}\text { Newfoundland } \\
\text { (3Ps) }\end{array}$ & $\begin{array}{l}\text { East } \\
\text { Greenland }\end{array}$ & Iceland & Iceland & $\begin{array}{c}\text { Georges } \\
\text { Bank }\end{array}$ & Iceland \\
\hline 1963 & 0.27 & & & & & & 0.22 & \\
\hline 1964 & 0.29 & & & & & & 0.19 & \\
\hline 1965 & 0.32 & & & & & & 0.16 & \\
\hline 1966 & 0.22 & & & & & & 0.21 & \\
\hline 1967 & 0.23 & & & & & & 0.23 & \\
\hline 1968 & 0.25 & & & & & & 0.35 & \\
\hline 1969 & 0.20 & & & & & & 0.32 & \\
\hline 1978 & & 0.09 & 0.10 & & & & & \\
\hline 1979 & & 0.23 & 0.28 & & & & & \\
\hline 1980 & & 0.38 & 0.17 & 0.17 & & & & \\
\hline 1981 & & 0.33 & 0.21 & 0.18 & & & & \\
\hline 1982 & & 0.13 & 0.19 & 0.26 & 0.28 & 0.27 & & 0.25 \\
\hline 1983 & & 0.68 & 0.21 & 0.14 & 0.17 & 0.19 & & 0.30 \\
\hline 1984 & & 0.12 & 0.18 & 0.25 & 0.20 & 0.12 & & 0.17 \\
\hline 1985 & & 0.14 & 0.15 & & 0.18 & 0.16 & & 0.23 \\
\hline 1986 & & & 0.14 & & 0.08 & 0.08 & & 0.09 \\
\hline
\end{tabular}

TABLE 12. Simulations of seven stratification schemes for cod in the northern area during 1986. $\left(\overline{\mathrm{Y}}_{\mathrm{st}}=\right.$ the stratified mean catch in numbers per tow, and $V_{r}=$ the relative standard error in $\%$.) The original stratification is indicated by $(0)$.

\begin{tabular}{cccc}
\hline $\begin{array}{c}\text { Stratification } \\
\text { scheme }\end{array}$ & $\overline{\mathrm{Y}}_{\mathrm{st}}$ & $\begin{array}{c}\text { Standard } \\
\text { error }\end{array}$ & $\mathrm{V}_{\mathbf{r}}$ \\
\hline$(0)$ & 300 & 24 & 8.0 \\
$(1)$ & 316 & 24 & 7.6 \\
$(2)$ & 288 & 22 & 7.6 \\
$(3)$ & 298 & 22 & 7.4 \\
$(4)$ & 307 & 23 & 7.5 \\
$(5)$ & 304 & 24 & 7.9 \\
$(6)$ & 305 & 22 & 7.2 \\
$(7)$ & 291 & 19 & 6.5 \\
\hline
\end{tabular}

of a bias in this context, since we are merely computing an index of abundance.

The interannual variability in precision observed in groundfish surveys in Arctic and Sub-Arctic regions, as well as the variable ratio of survey to VPA estimates observed in the present survey, demonstrates clearly the range of possible bias in groundfish stock measurments. The main sources of bias are presumably related to variable catchability, changes in patchiness, weather conditions and environmental conditions including availability of food. Some preliminary attempts have been made to analyse the interaction of these factors and the stock size indices in an ANCOVAtype model (Steinarsson et al., MS 1987). Apparently, the achievement of the main objective of this project depends to a substantial degree on the success of modeling of this kind.

\section{Acknowledgements}

During the sampling period 75 fishermen participated in this project. The skippers of the trawlers and their advisors also took an active part in the planning stage. Twenty-five members of the staff of MRI participated in the sampling. In addition several others were engaged in the planning process and other work. We are indebted to all these co-workers for their valuable contributions to the project. Further, we are indebted to Gudni Thorsteinsson for his expert advice on fishing gear and method, to Hjalmar Vilhjalmsson and Kjartar Thors for correcting the English manuscript, to Sigurdur Gunnarsson for drawing the figures and to Jakob Jakobsson, Director of MRI, for his dedicated support to the project.

\section{References}

BRODIE, W. B., and R. WELLS. MS 1985. The distribution of trawl catches of cod and American plaice for research vessel surveys in NAFO Division $3 \mathrm{~L}, 3 \mathrm{M}$ and $3 \mathrm{~N}$. NAFO SCR Doc., No. 106, Serial No. N1082, 14 p.

COCHRAN, W. G. 1953. Sampling techniques. John Wiley \& Sons, Inc., New York, $330 \mathrm{p}$.

CORNUS, H. P. MS 1985. Development of a bottom-trawl survey off East Greenland from 1980 to 1984. NAFO SCR Doc., No. 98, Serial No. N1074, 17 p.

GROSSLEIN, M. D. 1971. Some observations on accuracy of abundance indices derived from research vessel surveys. ICNAF Redbook, 1971(III): 249-266.

MABEAU, S., J. C. POULARD, and J. C. MAHE. MS 1986. 
Research survey abundance indices of the cod stock in NAFO Subdivision 3Ps, their reliability and compatibility with results of a cohort analysis. ICES C.M. Doc., No. G:38, $29 \mathrm{p}$.

PÁLSSON, O. K. MS 1984. Studies on recruitment of cod and haddock in Icelandic waters. ICES C.M. Doc., No. G:6, $18 \mathrm{p}$.

PÁLSSON, O. K., and G. THORSTEINSSON. MS 1985. The management of juvenile fish by-catch in an Icelandic shrimp fishery. ICES C.M. Doc., No. K:47, 19 p.

SCHOPKA, S. A., B. AE. STEINARSSON, and E. JONSSON.
MS 1983. Preliminary report of groundfish surveys in Icelandic waters in spring and autumn 1982 and spring 1983. ICES C.M. Doc., No. G:28, 26 p.

STEINARSSON, B. AE., and G. STEFANSSON. MS 1986. Comparison of random and fixed trawl stations in Icelandic groundfish surveys and some computational considerations. ICES C.M. Doc., No. D:13, 25 p.

STEINARSSON, B. AE., E. JONSSON, O. K. PÁLSSON, S. A. SCHOPKA, and G. STEFANSSON. MS 1987. Icelandic groundfish survey 1985-87. ICES C.M. Doc., No. G:32, $25 \mathrm{p}$. 